\title{
SITUAÇÃO DA AGRICULTURA IRRIGADA NO BRASIL DE ACORDO COM O CENSO AGROPECUÁRIO 2006
}

\author{
Janaina Paulino ${ }^{1}$, Marcos Vinicíus Folegatti ${ }^{1}$, Cornélio Alberto Zolin ${ }^{2}$, Rodrigo Máximo \\ Sánchez-Román ${ }^{3}$, Jefferson Vieira José ${ }^{1}$ \\ ${ }^{1}$ LEB/ESALQ/USP. Av. Pádua Dias, 11, CEP 13418-900, Piracicaba, SP. Fone:(19) 3447-8553. E-mail(s): \\ jpaulino@esalq.usp.br;mvfolega@esalq.usp.br \\ ${ }^{2}$ EMBRAPA/AGROSSILVIPASTORIL. Av. Dos Jacarandás, 2639, CEP 78550-003, Sinop, MT. Fone: (66) 3532- \\ 7626.E-mail: cornelio.zolin@embrapa.br \\ ${ }^{3}$ FCA/UNESP. Rua José Barbosa de Barros, 178, CEP 18610-307, Botucatu, SP. Fone: (14) 3711-7100. E-mail: \\ rmsroman@fca.unesp.br
}

\section{RESUMO}

O conhecimento das áreas irrigadas e sua distribuição geográfica no Brasil é de fundamental importância para o planejamento da gestão de recursos hídricos do país. A evolução da área irrigada de acordo com o método de irrigação possibilita identificar o uso de tecnologias de uso mais racional da água. Objetivou-se com a realização do presente trabalho sistematizar as informações sobre a área irrigada no Brasil e identificar os métodos que apresentaram a maior expansão nessa última década, com base nos censos agropecuários 1995/1996 e 2006. O Brasil apresenta atualmente uma área de 4,45 milhões de hectares irrigados. Observou-se que em relação ao censo anterior, a área irrigada aumentou 1,3 milhões de hectares, ou seja, 42\%. A regiãoSudeste ultrapassou a região Sul, que no censo 1995/96 possuía a maior área irrigada, a região Nordeste ocupa o terceiro lugar neste ranking com $22,12 \%$, já as regiões Centro-oeste e Norte somam juntas apenas $14,7 \%$. O método de irrigação mais utilizado segundo a classificação do censo agropecuário 2006 é o de aspersão (sem considerar o pivô), seguido pela inundação, pivô central, outros, localizada e sulco, representando 35,3\%, 24,4\%, 18,9\%, $8,3 \%, 7,4 \%$ e $5,8 \%$, respectivamente.

UNITERMOS: métodos de irrigação, estatística, IBGE, Brasil, irrigação, área irrigada

\section{PAULINO, J.; FOLEGATTI, M.V.; ZOLIN, C.A.; ROMÁN, R.M.S.; JOSÉ, J.V. BRAZIL AGRICULTURE IRRIGATED STATUS ACCORDING TO THE AGRICULTURAL CENSUS OF 2006}

\section{ABSTRACT}

Knowledge about irrigated agricultural area and its geographical distribution are of great importance to water resources management. Evolution of irrigated area according to the irrigation method allows an identification of rational water technologies. The aim of this work was to analyze the information presented in the agricultural census of 1995/1996 and of 2006 . Brazil has an area of 4.45 million cultivated hectares with irrigation. It is noticed that according to the 1995/1996 census, the irrigated area increased 1.3 million hectares, a growth of $42 \%$. The Southeast region surpasses the South region which had, in 1995/96, the largest 
irrigated area. The Northeast region is the third irrigated agricultural area with $22.12 \%$, while the Central-west and the Northern region together sum 14.7\%. According to the agricultural census 2006 classification, sprinkler irrigation (without center pivot) method is the most used, followed by flood, center pivot, other methods, drip and furrow, representing $35.3 \%, 24.4 \%$, $18.9 \%, 8.3 \%, 7.4 \%$ and $5.8 \%$, respectively.

KEYWORDS:Irrigation methods, statistic, IBGE, Brazil, irrigation, irrigated area

\section{INTRODUÇÃO}

Estima-se que a área irrigada no mundo ocupe cerca de $17 \%$ de toda a terra agricultável e responda pela produção de mais de $40 \%$ de todo o alimento consumido. A área irrigada mundialmente equivale a quase 2,5 vezes a produção de alimentos das áreas de sequeiro. No Brasil, cada hectare irrigado equivale a três hectares de sequeiro em produtividade física e a sete em produtividade econômica (Agência Nacional de Águas -ANA, 2004). Esses dados dão uma idéia da importância da prática da irrigação no contexto alimentar.

De acordo com Mukherjiet al. (2009) 80\% dos produtos necessários para satisfazer as necessidades da população mundial, nos próximos 25 anos, serão providos pelos cultivos irrigados. Por outro lado, a agricultura irrigada é a atividade humana que demanda a maior quantidade de água,em termos mundiais, estima-se cerca de $70 \%$ do uso da água, sendo que nos países em desenvolvimento este valor pode chegaraté $95 \%$, causando conflitos em relação aos demais usos da água (FoodandAgricultureOrganization - FAO, 2007). No Brasil o setor de irrigação é o que possui a maior parcela de vazão retirada (cerca de $47 \%$ do total) e a maior vazão de consumida(69\%) (ANA, 2009).

O Brasil apresenta 12\% da disponibilidade mundial de recursos hídricos (BRASIL, 2008), e possui um potencial de expansão para agricultura irrigada de cerca de 30 milhões de hectares, ou seja, um adicional de 25,5 milhões, considerando a área irrigada atual de aproximadamente 4,5 milhões, sendo assim, o país tem um grande potencial de aumento da área irrigada (MMA/SRH/DDH-1999 revisado por CHRISTOFIDIS, 2002).Contudo, esta expansão se torna uma questão estratégica, uma vez que implicará em uma maior demanda pelos recursos hídricos e energéticos e possíveis conflitos pelo uso da água.

Loiola\& Souza (2001) ressaltaram em seu trabalho a importância do uso das estatísticas do censo agropecuário sobre irrigação no país, pois segundo os autores, através delas é possível aprofundar os conhecimentos sobre a extensão da área irrigada e o uso dos métodos de irrigação, além de saber quais as regiõese, dentro de cada região, quais os estados onde a tecnologia da irrigação tem maior importância.

Nesse contexto, objetivou-se com a realização do presente trabalho, sistematizar as informações sobre a área irrigada no Brasil, bem como comparar estes dados com os já existentes na literatura e determinar as evoluções no que concerne aos métodos e sistemas de irrigação com base no censo agropecuário 2006. 


\section{MATERIAL E MÉTODOS}

A pesquisa foi realizada utilizando-se dados retirados do Censo Agropecuário 2006 (Instituto Brasileiro de Agricultura e estatística - IBGE, 2009) e comparando-os com os dados do censo 1995/96 (IBGE, 1998) e demais trabalhos encontrados na literatura.

A aquisição dos dados do Censo Agropecuário se deu através do Sistema IBGE de Recuperação Automática - SIDRA, sendo a tabela 855 a mais utilizada. Esta tabela corresponde a uma matriz multidimensional $(4 \times 7 \times 7 \times 5 \times 4 \times 12 \times 1 \times 6039)$, o qual foi possível obter as informações utilizadas no trabalho, como área irrigada pelos métodos correspondentes, por regiões administrativas e estados.

Para melhor compreensão dos dados deste trabalho, é importante entender como foram definidos alguns fatores utilizados na pesquisa realizada pelo IBGE. Paraisso, foi feita uma síntese de como foi realizada a pesquisa e as definições de alguns termos mais importantes seguem descritas abaixo.

No levantamento dos dados pesquisou-se a área total irrigada nos estabelecimentos agropecuários e os respectivos métodos de irrigação utilizados, e ainda se uma mesma área tinha sido irrigada mais de uma vez ou se uma mesma área tinha sido irrigada por métodos diferentes. Considerou-se como irrigação: a prática de aplicar água, que não a da chuva, diretamente à superfície do solo cultivado com pastos ou culturas, em quantidades e intervalos determinados, com a finalidade de fornecer água às plantas em condições apropriadas ao seu crescimento e produção.

Os métodos foram definidos da seguinte forma: 1. Inundação- consiste no nivelamento do terreno para alagamento ou inundaçãoda área de cultivo de determinadas lavouras; 2 . Sulcos- consiste na condução e distribuição da água através de sulcos ou canais de irrigação localizados entre linhas de plantio das culturas; 3 . Pivô-central- considera o método no qual a área é irrigada por sistema móvel, constituído por uma barra com aspersores, que se movimenta em torno de um ponto fixo; 4.Aspersão-foram considerados como aspersores fixos e móveis, exceto pivô-central (aspersão convencional e autopropelido); 5. Localizadaconsiderou-se o gotejamento, microaspersão e outros;6. Outros- consiste em irrigações manuais utilizandoregadores, mangueiras, baldes, latões e outros métodos.

\section{RESULTADOS E DISCUSSÃO}

\section{1 Área irrigada por região}

De acordo com dados da ANA (2009) desde 1960 até 1995/96 (Figura 1), a área irrigada no país aumentou de 0,45 milhões de hectares para 3,1 milhões de hectares em 199596, sendo cerca de $90 \%$ dessas áreas irrigadas desenvolvidos pela iniciativa privada, e os restantes $10 \%$ por projetos públicos (ANA, 2009). Ainda na Figura 1 é possível notar que a região sul foi a que sempre apresentou a maior área irrigada, até o ano de 1996, seguida pela região sudeste, nordeste, centro-oeste e norte. 


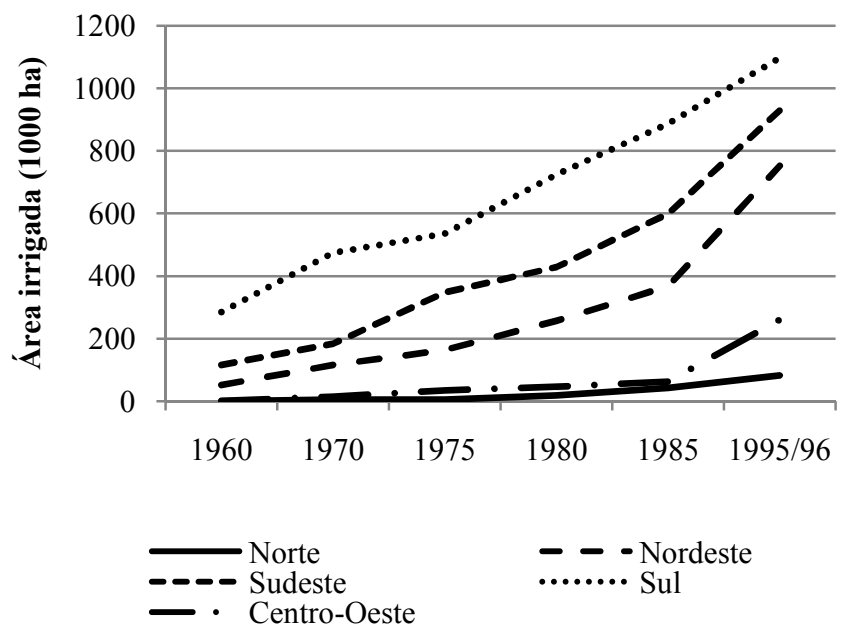

Figura 1. Evolução da área irrigada no Brasil(Adaptado de ANA, 2009)

Analisando e comparando os dados obtidos pelo censo agropecuário de 1995-1996 com os obtidos pelo censo agropecuário de 2006 (Figura 2), observa-se que a área irrigada no país deu um salto de 3.121.644para 4.453.925 ha, o que representou um aumento de 1,3 milhões de hectares, ou seja, $42 \%$ em aproximadamente 10 anos, o que resulta em um ritmo médio de 150 mil hectares por ano.

O Brasil possui uma estimativa de 29.564 .000 ha com potencial para o uso de irrigação (CHRISTOFIDIS, 1999), sendo que, atualmente (censo 2006)estão sendo explorados aproximadamente $15 \%$ deste potencial $(4.453 .925 \mathrm{ha})$.

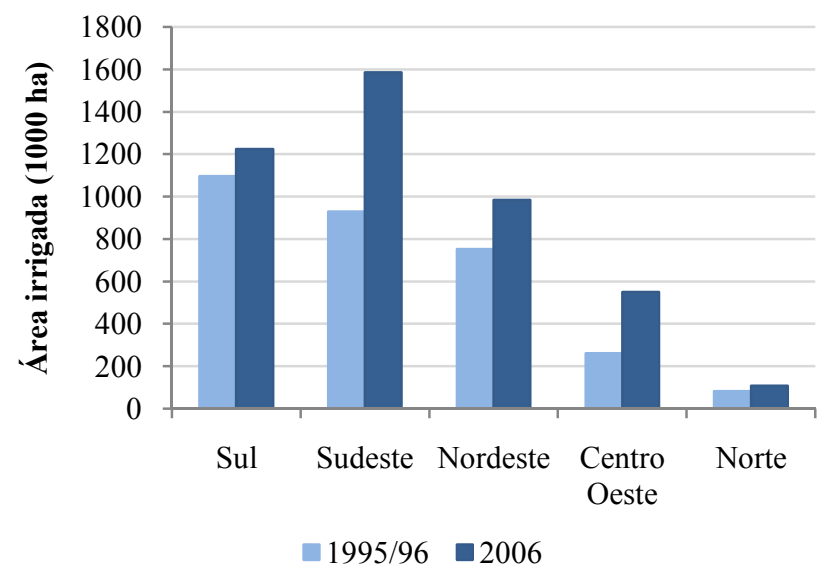

Figura 2. Evolução da área irrigada no Brasil nos dois últimos levantamentos do censoagropecuário

Com esses números o Brasil assume o $16^{\circ}$ lugar entre os países com maior área irrigada no mundo, detendo pouco mais de $1 \%$ da área mundial irrigada, que é cerca de 277 milhões de hectares (ANA, 2009).É um dos países com menor relação "área irrigada/área irrigável", além de exibir baixíssima taxa de hectares irrigados/habitante (0,018 ha/habitante), a menor da América do Sul (ANA, 2009). Esta baixa relação área irrigada/área irrigável justifica-se, em parte, pela boa distribuição de chuvas em boa parte do território nacional ao longo de determinadas épocas do ano. 
Verifica-se, nesta última década (Figura 2), que houve uma inversão entre as regiões Sudeste e Sul, pois até o censo de 1995/96 a região Sul com 1.195.440 ha, era a que possuía a maior área irrigada $(35,1 \%)$, contra 890.974 ha $(29,8 \%)$ da região Sudeste que apresentava a segunda maior área.Atualmente, a região Sudeste encontra-se com 1,58 milhões de hectares irrigados, representando $35,6 \%$ da área total do país e a região Sul apresenta uma área de 1,22 milhões de hectares $(27,5 \%)$.

Christofidis (2002) fez um levantamento da área irrigada no Brasil no ano de $2001 \mathrm{e}$ verificou que a região Sul ainda apresentava a maior área irrigada, o que implica que o aumento da área irrigada na região Sudeste se deu entre os anos de 2002 e 2006.

Essa inversão se deve, possivelmente, ao fato de a região sudeste possuir uma relação entre a área potencial irrigável e a área efetivamente irrigadamaior do que a da região Sul. De acordo coma Secretaria Extraordinária da Irrigação e Usos Múltiplos da Água - SEIUMA (2010) a região Sudeste possui 5,9 milhões de hectares potenciais para o desenvolvimento da irrigação, enquanto que a região Sul possui cerca de 4,5 milhões, considerando as várzeas.

Com $22,1 \%$ de toda área irrigada do país, a região Nordeste assume o terceiro lugar, seguida das regiões Centro-Oeste e Norte, que possuemmenor expressão.Juntas, somam cerca de $14,7 \%$ da área total irrigada.Analisando os métodos de irrigação utilizados, pode-se observar que os sistemas de irrigação por aspersão (S/PIVO) é empregado na maior parte das áreasirrigadas, com 1.572.960 ha(35\%), seguido pelainundação (24\%), pivô-central (19\%), localizada ( $8 \%$ ) e outros $(8 \%)$ e por último a irrigação por sulcos com $6 \%$ (Figura 3 ).

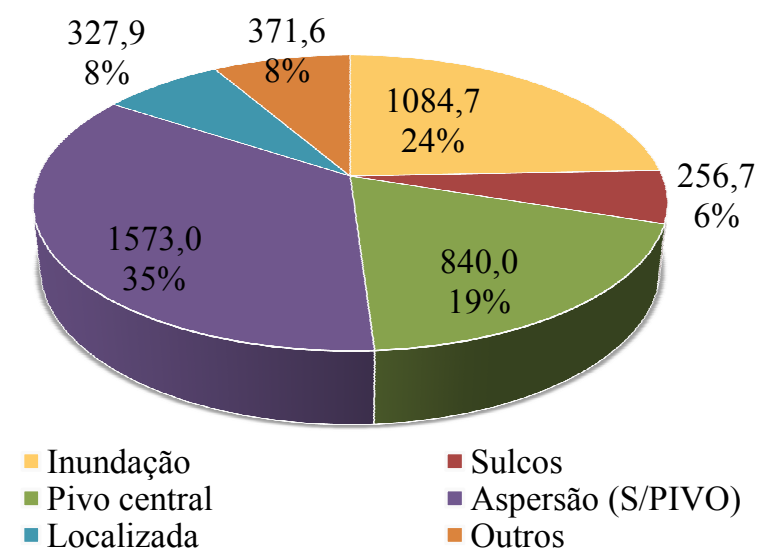

Figura 3. Área (1000 ha) e porcentagem de área irrigada no Brasil para os diferentes métodos de irrigação

Na Figura 4 estão apresentadas as porcentagens de áreas irrigadas nas diferentes regiões para os métodos de irrigação utilizados. Pode-se notar que $85 \%$ da irrigação por inundação do Brasil encontra-se na região Sul. A área irrigada por sulcos é melhor distribuída entre as regiões, a região nordeste é responsável pela utilização de $43 \%$ do uso deste sistema, seguida pela região Sul (32\%), centro-oeste (13\%), sudeste $(11 \%)$ e norte com somente $1 \%$.

Para os demais métodos de irrigação (pivô-central, aspersão (S/PIVO), localizada e outros) observa-se que a região sudeste apresentou as maiores porcentagens de área irrigada, seguida da região nordeste. 


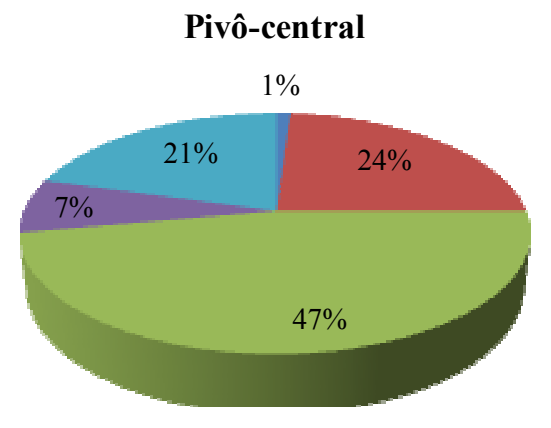

Aspersão (S/PIVO)

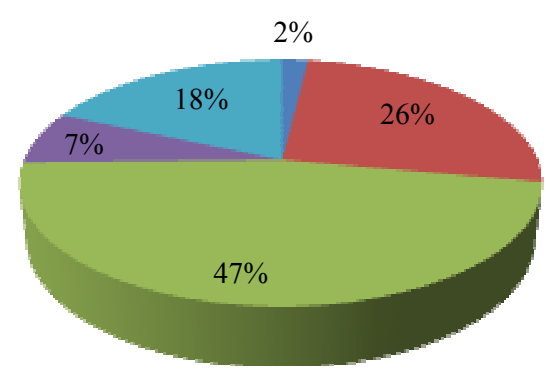

Localizada

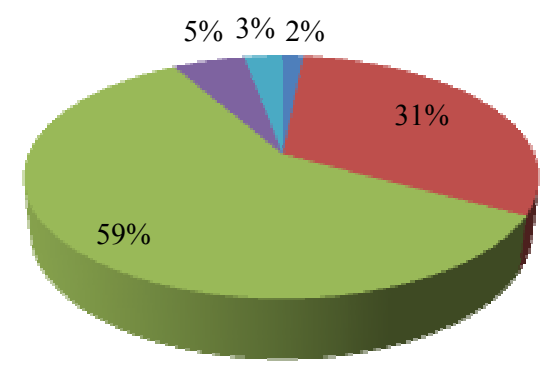

Inundação

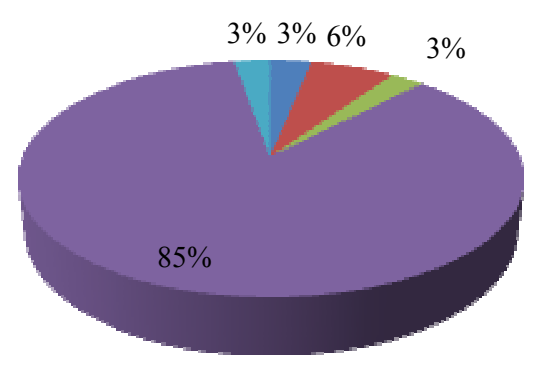

Sulcos

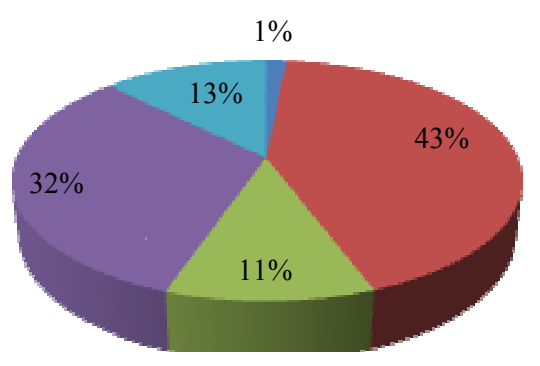

Pivô-central

$1 \%$

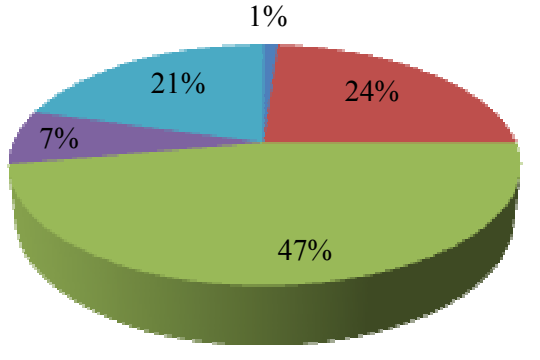

Figura 4. Porcentagem de área irrigada nasregiões brasileiras para cada método de irrigação

A porcentagem de distribuição dos métodos de irrigação nas regiões brasileiras pode ser visualizada na Figura 5 e a distribuição em hectares encontra-se descrito na Tabela $1 . \mathrm{Na}$ região sudeste, que possui a maior área irrigada, o método de irrigação por aspersão (pivôcentral mais aspersão S/PIVO) representa mais de $70 \%$ da área irrigada, sendo o método aspersão (S/PIVO) o mais representativo com 736.589 ha, ou seja, 46\%, já a inundação e sulcos juntos somam menos de $4 \%$ do total.

Assim como na região Sudeste, a irrigação por aspersão foi também predominante nas regiões Nordeste (609.052 ha) e Centro-oeste (462.950 ha). No Nordeste a aspersão(sem pivô) representou $41,4 \%$ e o pivô-central $20,4 \%$, já no centro-oeste a aspersão (sem pivô) representou $52,8 \%$ e o método pivô-central $31,5 \%$.

Diferentemente doque ocorre nas demais regiões, o método mais utilizado na região sul (segunda maior região em área irrigada), é a inundação, esta representa $75 \%$ de toda a área, com 923.826 ha irrigados, isso se deve ao fatoda ampla área cultivada com arroz irrigado no estado do Rio Grande do Sul, pois de acordo com Weber et al. (2007), este estado possuicerca de 725 mil ha de arroz sob irrigação. Em contraste, o método menos utilizado na região sul é o de irrigação localizada, com apenas $1,4 \%$ do total. 


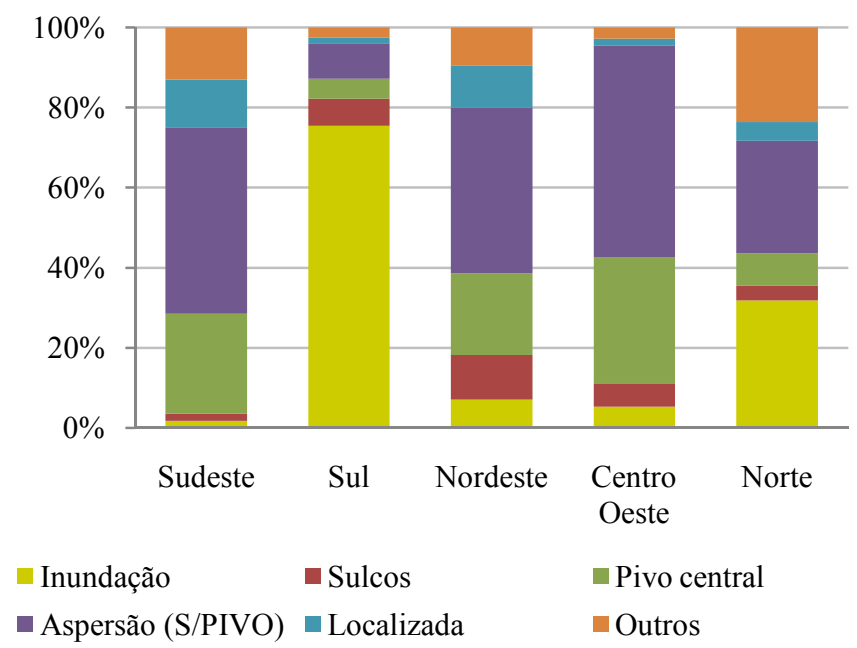

Figura 5. Distribuição percentual dos métodos de irrigação em cada região administrativa do Brasil

Tabela 1. Distribuição da área irrigada nas regiões administrativas e métodos de irrigação

\begin{tabular}{cccccccc}
\hline \multirow{2}{*}{ Região } & \multicolumn{7}{c}{ Métodos (1000 ha) } \\
\cline { 2 - 8 } & Inund. $^{1}$ & Sulcos & Pivô $^{2}$ & Asp. $^{3}$ & Loc. $^{4}$ & Outros & Total \\
\hline Sudeste & 27,74 & 28,32 & 395,59 & 736,59 & 192,81 & 205,69 & 1586,74 \\
Sul & 923,83 & 82,55 & 61,35 & 108,43 & 17,65 & 30,77 & 1224,58 \\
Nordeste & 69,62 & 109,71 & 201,28 & 407,77 & 102,97 & 93,99 & 985,34 \\
Centro-Oeste & 29,24 & 32,18 & 173,05 & 289,89 & 9,41 & 15,69 & 549,46 \\
Norte & 34,31 & 3,9 & 8,78 & 30,28 & 5,02 & 25,5 & 107,79 \\
\hline
\end{tabular}

${ }^{1}$ Inundação, ${ }^{2}$ Pivô Central, ${ }^{3}$ Aspersão (S/PIVO), ${ }^{4}$ Localizada

Com estas informações em relação aos métodos de irrigação praticados no Brasil, pode-se constatar que a agricultura irrigada deste país se encontra em uma posição diferenciada quando comparada com os demais países. Enquanto na maior parte do mundo se utiliza os métodos de irrigação por superfície, no Brasil a irrigação pressurizada é a que mais se destaca.

Embora com todas as problemáticas relativas ao manejo da água sem preocupação em relação a sustentabilidade dos recursos hídricos e consequentementeatrelado a baixa eficiência de irrigação (média 65,26\%), conforme pode ser observado em Christofidis (2008),o fato da agricultura brasileira possuirem maior quantidade, sistemas de irrigação pressurizados, remete a possibilidade de melhorias significativas no uso racional da água, tendo em vista que incrementosrelevantes naeficiência do uso da água em sistemas por aspersão podem ser obtidosmais facilmente do que em sistemas por superfície,com a adequação de práticas básicas no manejo da irrigação.

Christofidis (2008) comenta que o problema com a baixa eficiência da irrigação está melhorando ano a ano porém ainda é um desafio essencial da agricultura irrigada. 


\section{2 Área irrigada por estado}

\section{Região Norte}

A região Norte, maior do País, com 387 milhões de ha (45,3\% do território nacional) é uma região muito rica em água, porém pouco ocupada e desenvolvida (ANA, 2003). Esta região apresenta a menor área irrigada do Brasil com apenas 107.789 ha, sendo este valor $2,4 \%$ do total. Esta região teve um acréscimo de $29 \%$ da área irrigada quando comparada com o censo de 1995/96, sendo uma das menores do Brasil. É importante destacar que a região compreende parte do trópico úmido brasileiro e a maior parte da Floresta Amazônica.

O estado do Tocantins é o maior irrigante da região Norte representando 38,4\% das áreas, seguido pelo estado do Pará.Estes dois estados somam juntos 70.673 ha, ou seja, 65,6\% do total irrigado na região. Entre os métodos, a irrigação por inundação é a mais utilizada, seguida pela aspersão (S/PIVO) e outros métodos (Figura 6).

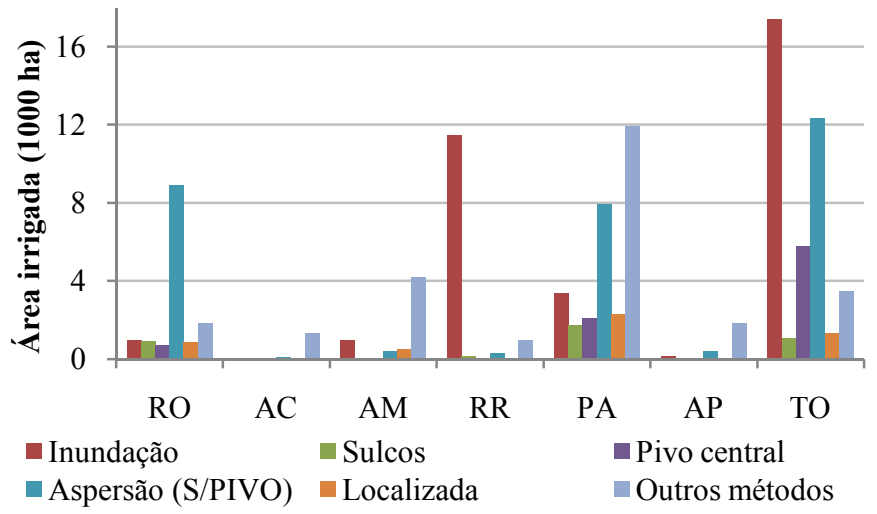

Figura 6. Área irrigada pelos diferentes métodos nos estados da região norte

\section{Região Nordeste}

A região Nordeste, de acordo com ANA (2003) possui 156 milhões de ha (18\% do território nacional) e sua população ultrapassa $28 \%$ da população do País, ocupando a maior parte da região semi-árida do Brasil. Éa terceira colocada no ranking de área irrigada no Brasil, mantendo a sua colocação ao longo dos anos. Com uma expansão de $31 \%$ em relação aos últimos dois censos, possuí atualmente 985.348 ha irrigados dos 1.200 .000 de ha aptos para irrigação (sem várzea), o que revelaestudos desenvolvidos pelo MMA/SRH/DDH (1999) revisados por Christofidis (2002) (CHRISTOFIDIS, 2006).

O estado da Bahia representa $30,4 \%$ da irrigação da região Nordeste com aproximadamente 300 mil ha irrigados, sendo o método de irrigação por aspersãomais utilizado no estado, tanto aspersão S/PIVO (30,6\%) quanto pivô-central $(23,1 \%)$.

As maiores áreas irrigadas por aspersão (S/PIVO) e por pivô-central na região, são do estado de Alagoas, sendo 110.049 ha e 73.041 ha, respectivamente, já os demais métodos são pouco representativos em área irrigada.

O método de aspersão (S/PIVO) destaca-se também nos demais estados, com exceção do Piauí que utiliza emmais de $30 \%$ da área irrigada do estado o método de inundação. Contudo, a representação do estado na região nordeste é de apenas 2,3\% (Figura 7). 


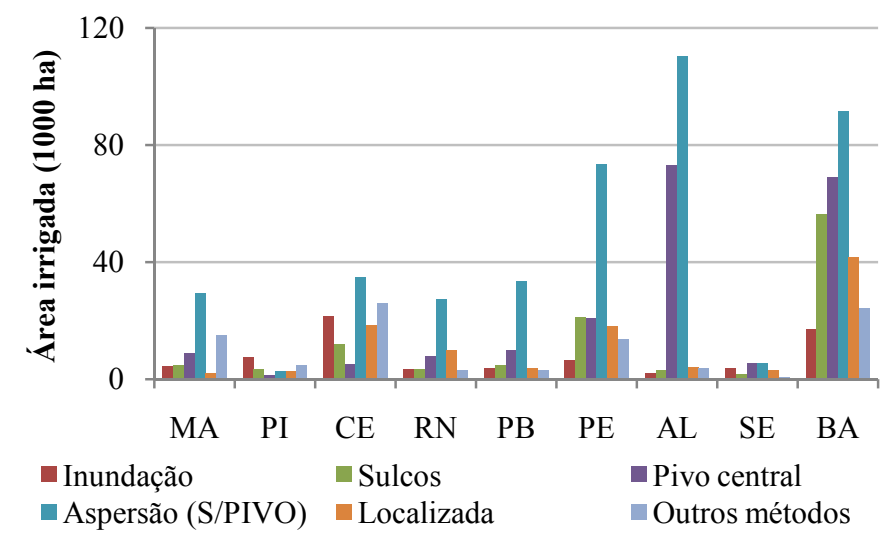

Figura 7. Área irrigada pelos diferentes métodos nos estados da região nordeste

\section{Região Sudeste}

A região Sudeste, com 92,7 milhões de ha (10,9\% do território nacional), abriga a maior parcela da população brasileira, com 72,4 milhões de habitantes, que corresponde a $42,6 \%$ da população. Além disso, esta região é a mais industrializada e de maior produção agrícola do País (ANA, 2003).

A região tem, de acordo com Christofidis (1999), 4.429.000 ha aptos para irrigação (sem várzea) e sua área irrigada em 2006 foi de 1.586 .744 ha. Teve um aumento de $70,8 \%$ de área irrigada,quando se compara os dois últimos levantamentos do censo agropecuário. Tal região aumentou sua área irrigada em mais de 650 mil hectares, com destaque para o estado de SP que teve uma expansão de 330 mil ha (Figura 8). Considerando que esta região possuía a segunda maior área irrigada em 1995/96 (929.189 ha), este acréscimo foi o suficiente para que a região sudeste ultrapassasse a região sul, assumindo o primeiro lugar.

O estado de São Paulo representa quase $50 \%$ da irrigação da região sudeste com uma área de 770.011 ha, esta área é equivalente a soma das áreas irrigadas nas regiões norte e centro-oeste. O sistema de irrigação mais utilizado no estado é o de aspersão (S/PIVO) com $53 \%$ e o pivô-central com $25,3 \%$ da área irrigada.

A aplicação de vinhaça é feita em grande parte com o sistema autopropelido. Levando em conta que nos últimos anos o cultivo de cana-de-açúcar para produção de etanol está expandindo e que consequentemente a produção de vinhaça aumenta proporcionalmente, acredita-se que uma das razões para o aumento brusco da área irrigada na região Sudeste foia consideração da aplicação de vinhaça no solo como irrigação.

Com 33,1\% da área irrigada da região sudeste, está o estado de Minas Gerais (525.250 ha). Assim como em São Paulo o sistema de irrigação por aspersão é o que prepondera entre os demais, sendo $32 \%$ para aspersão (S/PIVO) e 31,7\% para pivô-central.O Rio de Janeiro é o estado menos expressivo, com somente 81.683 ha irrigados. Em relação aos métodos de irrigação, os menos utilizados em todos os estados da região sudeste são o método de inundação e o por sulcos. 


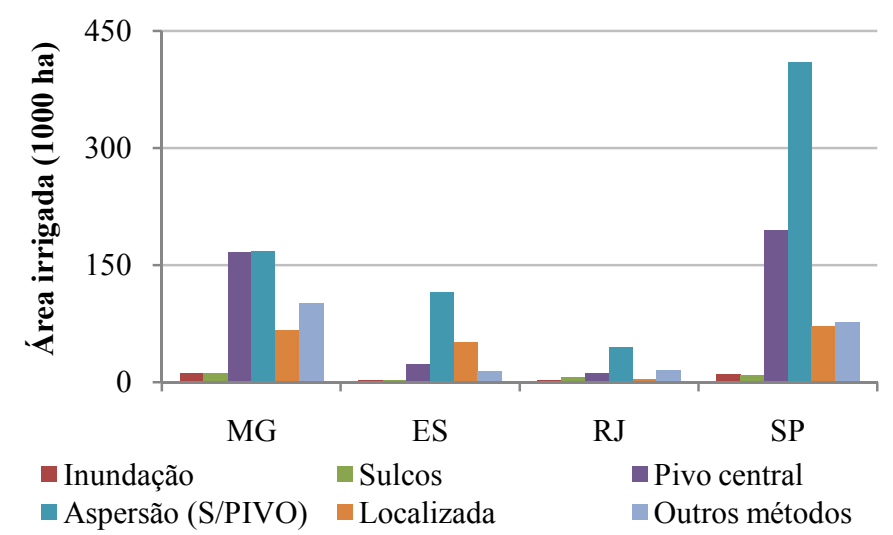

Figura 8. Área irrigada pelos diferentes métodos nos estados da região sudeste

\section{Região Sul}

Essa região tem 57,7 milhões de ha (6,8\% do território nacional) e abriga $14,8 \%$ da população brasileira, possui clima temperado ou subtropical úmido e precipitações bem distribuídas ao longo do ano (ANA, 2003).

Diferentemente da região Sudeste, a área irrigada na região sul aumentou apenas 11,7\% com relação ao censo 1995/96, conforme foi observado, e este acréscimo foi bastante inferior ao ocorrido na região sudeste, fato que impossibilitou a região Sul de permanecer em primeiro lugar em relação a área irrigada.De acordo com Christofidis (1999) esta região possui 4.407.000 ha em terras (sem várzea) consideradas por ele aptas para a irrigação, este número, por sua vez, é menor do que a região sudeste.

O estado do Rio Grande do Sul é responsável por mais de $80 \%$ da irrigação na região sul e dos 984.085 ha irrigados no estado $82,6 \%$ são irrigados pelo método de inundação. Em Santa Catarina o método que prevalece também é o de inundação, porém a área irrigada neste estado representa apenas $11 \%$ de toda a região. O estado do Paraná é pouco representativo em área irrigada, possui apenas $8,5 \%$ do total irrigado na região sul, sendo que, diferentemente dos outros estados da região, o método mais utilizado é o de aspersão que é empregado em $53,8 \%$ das áreas irrigadas (Figura 9).

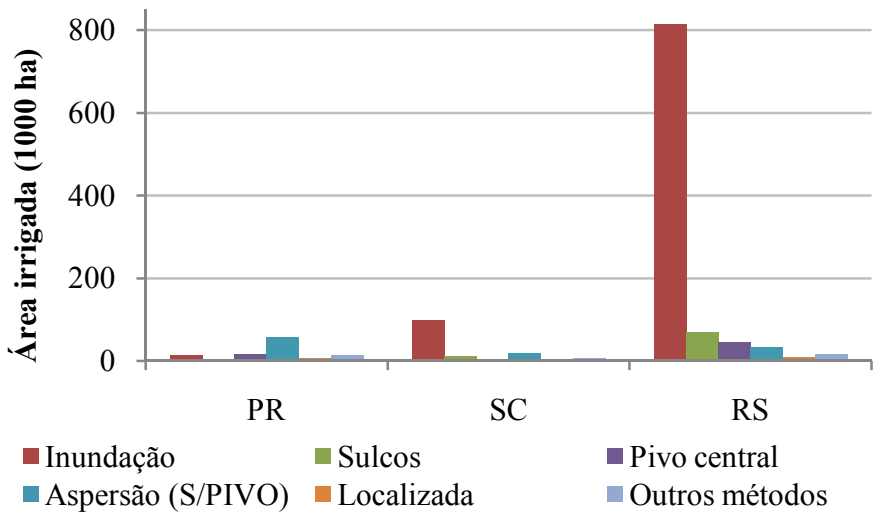

Figura 9. Área irrigada pelos diferentes métodos nos estados da região sul

É notável que as áreas disponíveis para a irrigação estejam decrescendo com o aumento da irrigação ao longo dos anos, neste sentido torna-se lógico o fato da região sul ser ultrapassada pela região sudeste, uma vez que quase toda a irrigação da região Sul é efetuada 
por basicamente um estado, provavelmente já não há a mesma área disponível para o acréscimo da irrigação como na região sudeste, cuja contribuição para o acréscimo da área irrigada vem de três estados.

\section{Região Centro-oeste}

A região centro-oeste é a região de expansão da fronteira agrícola no País (ANA, 2003), com 161 milhões de ha(18,9\% do território nacional). Possui de acordo com Christofidis (1999) 7.724.000 haaptos para o uso da irrigação efoi a região que teve,em porcentagem, o maior acréscimo em área irrigada nos últimos dez anos, sua área passou de 260.952 ha para 549.466 ha, isto representa110,6\% de acréscimo, porém esta região é a quarta colocada em área irrigada do país.

Goiás é o estado com maior área irrigada da região, tem 269.921 ha que equivalem a quase $50 \%$ da área irrigada, sendo que desta área $88 \%$ é realizada por aspersão (pivô-central e aspersão S/PIVO).O estado de Mato Grosso possui 148.425 ha irrigados, ondea soma dos métodos pivô-central e aspersão (S/PIVO) equivalem a 92,6\% da área irrigada.O estado do Mato Grosso do Sul é menos representativo em relação a área irrigada na região, possui cerca 116.612 ha, representando $21 \%$ das áreas irrigadas da região Centro-Oeste (Figura 10).

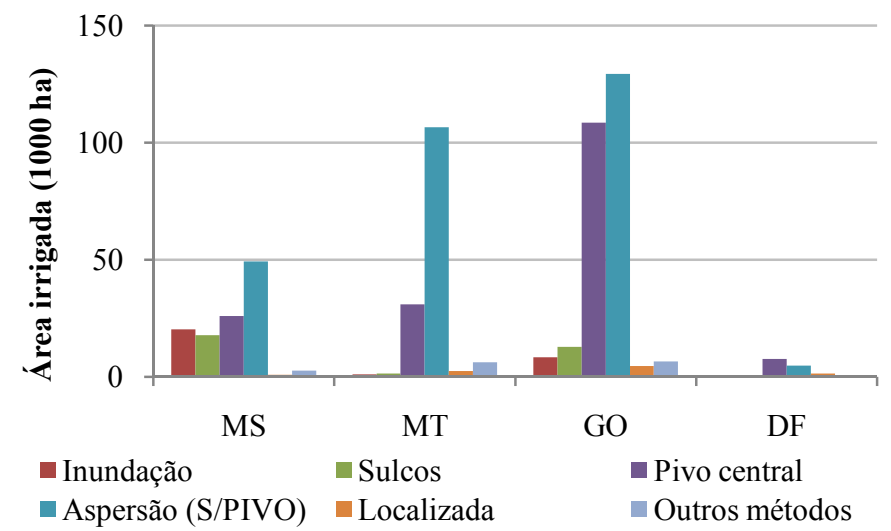

Figura 10. Área irrigada pelos diferentes métodos nos estados da região centro-oeste

\subsection{Expansãoda área irrigada nos estados}

Para um balanço geral das análises realizadas tanto no âmbito das regiões quanto dos estados, foi feito um ranking dos dez maiores estados irrigantes do Brasil, que pode ser visualizado na Figura 11.

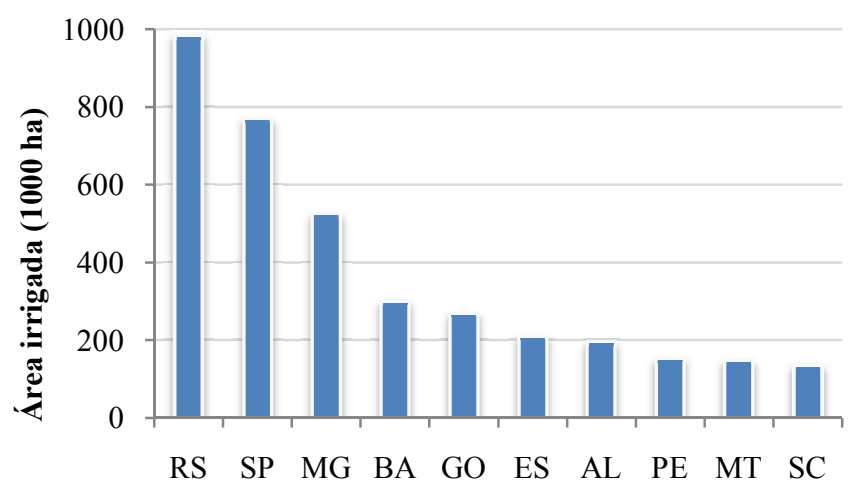

Figura 11. Relação dos dez estados com maior área irrigada no Brasil 
Observa-se que o Rio Grande do Sul, São Paulo e Minas Gerais apresentam as maiores áreasirrigadas, juntos somam 2.279.346 ha o que representa mais de $50 \%$ de toda a área irrigada do Brasil, sendo que somente o Rio Grande de Sul é responsável por 22\% destas áreas.

Dos três estados da região sul, dois (RS e SC)estão entre os dez maiores irrigantes, na região sudeste é semelhante, dos quatro estados, três (SP, MG e ES) estão listados. Estes dez estados relacionados representam $83 \%$ de toda área irrigada no Brasil.

Na Figura 12 é possível ver a diferença, em área irrigada, entre os levantamentos do censo agropecuário de 1995/96 e 2006, o estado de São Paulo sozinho teve uma expansão de 330.957 ha, Minas Gerais 202.571 ha e Espírito Santo 117.106 ha. Neste sentido pode-se relacionar o fato da região sudeste assumir o primeiro lugar em área irrigada do Brasilà contribuição da expansão destes estados.

A suposição de que o aumento da área irrigada na região Sudeste se deu pelo fato de considerar aplicação de vinhaça como irrigação pode ser entendida ainda, considerando que o estado de São Paulo é o maior produtor de cana-de-açúcar e este foi o estado com maior expansão de área irrigada nos últimos anos.

Um estado que também é destaque e que pertence a região centro-oeste, éGoiás, este estado apresentou uma expansão de 154.013 ha, ou seja, 133\% com relação ao levantamento do censo 1995/96. Mato Grosso e Mato Grosso do Sul, também da região centro-oeste, expandiram suas áreas irrigadas em 89.199 ha e 43.384 ha respectivamente.

Dos estados da região sul, o Paraná foi o estado que apresentou a maior expansão, 122\% (57.354 ha). Da região Nordeste os estados da Bahia, Maranhão, Alagoas e Pernambuco tiverem grande aumento conforme pode ser observado, masalguns estados apresentaram áreas menores do que as observadas no levantamento de 1995/96, como Paraíba, Amapá e Tocantins, sendo que Tocantins diminuiu em 20.129 ha suas áreas com irrigação.

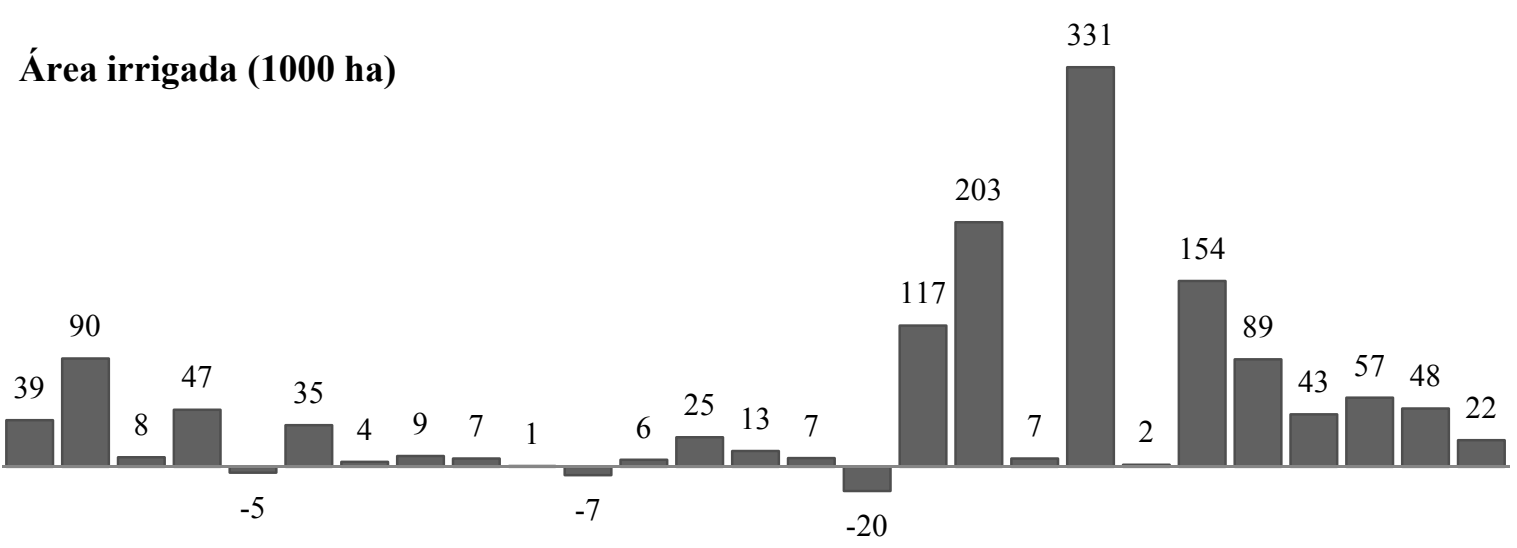

AL BA CE MA PB PE PI RN SE AC AP AM PA RO RR TO ES MG RJ SP DF GO MT MS PR RS SC

Figura 12. Diferença da área irrigada nos levantamentos do censo de 2006 e 1995/96

\section{CONCLUSÕES}

A sistematização dos dados do censo agropecuário de 2006 possibilitou identificar a expansão da área irrigada brasileira em relação ao censo de 1995/1996 em cada região 
administrativa, bem como determinar quais os métodos de irrigação mais utilizados por regiões administrativas e estados.

A área total irrigada no Brasil é de 4.453.925 ha, sendo que os métodos de irrigação mais representativos em ordem decrescente são os de aspersão (S/PIVO), inundação, pivô central, outros métodos, localizada e sulcos.

As regiões com as maiores áreas irrigadas do Brasil são respectivamente a Sudeste $(35,6 \%)$, Sul $(27,5 \%)$, Nordeste $(22,12 \%)$,Centro-Oeste $(12,3 \%)$ e Norte $(2,4)$ sendo a região Centro-Oeste a que apresentou a maior expansão em área irrigada com 110,6\%. Brasil.

A região Sudeste assumiu o primeiro lugar das regiões com maior área irrigada no

\section{REFERÊNCIAS}

BRASIL, Agência Nacional de Águas.Agricultura irrigada: estudo técnico preliminar. Brasília, DF, 2004, 107p.

BRASIL, Agência Nacional de Águas.Conjuntura dos recursos hídricos no Brasil 2009. Brasília, DF, 2009. Disponível em: <http://conjuntura.ana.gov.br/>. Acesso em:15 jun 2010.

BRASIL. Ministério da Integração Nacional. A irrigação no Brasil: situação e diretrizes. Brasília, 2008.

BRASIL. Agência Nacional de Águas,Plano Nacional dos Recursos Hídricos. Brasília, DF, 2003.

CHRISTOFIDIS, D. Água: Gênesis, gênero e sustentabilidade alimentar no Brasil.Brasilia, DF: Disponível em: < http://www.pt.genderandwater.org/page/2762>

CHRISTOFIDIS, D. Água, irrigação e segurança alimentar. Ministério da Integração Nacional. Série Irrigação e água: I 2008. Brasília: IICA, 2008.

CHRISTOFIDIS, D. Considerações sobre conflitos e uso sustentável em recursos hídricos, em Conflitos e uso sustentável dos recursos naturais, Suzi Huff Theodoro (org), Brasília: Garamont, 2002.

CHRISTOFIDIS, D. Recursos Hídricos e Irrigação no Brasil. Brasília: CDS - UnB, 1999. FAO.2007. Agriculture and water scarcity: a programmatic approach to water use efficiency and agricultural productivity. Twentieth Session, Committee on Agriculture, COAG/2007/7. Rome.

MUKHERJI, A.; et. al. Revitalizing Asia's irrigation: to sustainably meet tomorrow's food needs. Colombo, Sri Lanka: International Water Management Institute; Rome, Italy: Food and Agriculture Organization of the United Nations, 2009.

LOIOLA, M. L.; SOUZA, F. Estatísticas sobre irrigação no Brasil segundo o Censo Agropecuário 1995-1996. Revista Brasileira de Engenharia Agrícola e Ambiental, Campina Grande, v. 5, n.1, p.171-180, 2001. 
INSTITUTO BRASILEIRO DE GEOGRAFIA E ESTATÍSTICA. Censo agropecuário 2006. Rio de Janeiro, 2009.

INSTITUTO BRASILEIRO DE GEOGRAFIA E ESTATÍSTICA. Censo agropecuário 1995-1996. Rio de Janeiro, 1998.

SEIUMA. Secretaria Extraordinária da Irrigação e Usos Múltiplos da Água, RS. Potencial brasileiro para desenvolvimento sustentável da irrigação. Disponível em: $<$ http://www.siuma.rs.gov.br/index.php?action=noticia\&cod=191>. Acesso em:10 fev 2010.

WEBER, E. J.; WAGNER, A. P. L.; FONTANA, D. C.; DUCATI, J. R.Estimativa de área cultivada com arroz irrigado no Rio Grande do Sul na safra 2005/2006 através de imagens Landsat. In: SIMPÓSIO BRASILEIRO DE SENSORIAMENTO REMOTO, Florianópolis, 2007, Anais XIII, INPE, p. 465-472. 